10 Chen YH, Stapleton FB, Roy S III, Noe HN. Neonata hypertension from a unilateral multicystic dysplastic hypertension from a unilateral
kidney. $f$ Urol 1985; 133: 664 .

11 Dimmick JE, Johnson HW, Coleman GU, Carter M. Wilms tumor, nodular renal blastema and multicystic renal dystumor, nodular renal blastema

12 Gordan AC, Thomas DFM, Arthur RJ, Irving HC Multicystic dysplastic kidney: is nephrectomy stil appropriate? F Urol 1988; 140: 1231-4.

13 Pedicelli G, Jequier S, Bowen AD, Boisvert J. Multicystic dysplastic kidneys: spontaneous regression demonstrated with US. Radiology 1986; 161: 23-6.
14 Avni EF, Thoua Y, Lalmand B, Didier F, Droulle P Schulman CC. Multicystic dysplastic kidney: natural history from in utero diagnosis and postnatal follow up. $f$ hrol 1987; 138: 1420-4.

15 Vinocur L, Slovis TL, Perlmutter AD, Watts FB, Chang $\mathrm{CH}$. Follow-up studies of multicystic dysplastic kidneys. Radiology 1988; 167: 311-5.

16 Rickwood AMK, Anderson PAM, Williams MPL Multicystic renal dysplasia detected by prenatal ultrasonography. Natural history and results of conservative management. Br $\mathcal{F}$ Urol 1992; 69: 538-40.

\title{
Eye poking - comme avec un tisonnier
}

Some rub their eyes, some press them, and some poke them. These behaviours have been lumped together as 'oculodigital phenomena' but workers in Vancouver (James E Jan and colleagues, Developmental Medicine and Child Neurology 1994; 36: 321-5) have pointed out that their associations are different. Eye rubbing is normal; it is a commonplace observation that most children and many adults rub their eyes when they are tired. Eye pressing occurs in children with severe bilateral congenital visual impairment due to disease of the eyes often when they are bored or anxious and sometimes while listening to music. Children with cortical blindness do not do it. (Some paediatric neurologists have been known to do it but not, so far as is generally known, to themselves.) It is not harmful. Eye poking, though, is a different matter, being very definitely harmful. Here the child pokes painfully at the eye, usually with the ipsilateral forefinger. Among 500 highly selected children referred to the Visually Impaired Programme of the Children's Hospital in Vancouver, 21 were given to eye poking. All 21 suffered from multiple handicapping conditions with severe global learning disorder. Fifteen of them were visually impaired but that was thought to represent ascertainment bias and there was no correlation between the degree of visual loss and the severity of eye poking. There were often other self injurious behaviours such as head banging, hand biting, hair pulling, and face slapping. Eye poking was more common in boys (13 boys, eight girls) but, strangely, the authors do not mention Lesch-Nyhan syndrome. The behaviour led to enucleation of an eye in one child and corneal scarring in three others. Retinal detachment, cataracts, ocular infection, and intraocular bleeding have all been described. These authors give a list of drugs which have been suggested and recommend behaviour modification but no treatment seems to have been successful.

Developmental Medicine and Child Neurology provides French, German, and Spanish translations of its summaries. I enjoyed the French translation of eye poking; 'se fourrer le doigt sur l'oeil, comme avec un tisonnier' (to stick your finger in your eye, as with a poker). Quite so! 